\title{
BMJ Open Protocol and statistical analysis plan for the Pragmatic Investigation of optimaL Oxygen Targets (PILOT) clinical trial
}

Matthew W Semler (D) , ${ }^{1}$ Jonathan D Casey, ${ }^{1}$ Bradley D. Lloyd, ${ }^{2}$ Pamela G. Hastings, ${ }^{2}$ Margaret Hays, ${ }^{1}$ Megan Roth, ${ }^{1}$ Joanna Stollings, ${ }^{3}$ John Brems, ${ }^{4}$ Kevin George Buell, ${ }^{4}$ Li Wang, ${ }^{5}$ Christopher J. Lindsell, ${ }^{5}$ Robert E. Freundlich, ${ }^{6}$ Jonathan P. Wanderer, ${ }^{6}$ Gordon R. Bernard, ${ }^{1}$ Wesley H. Self, ${ }^{7}$ Todd W. Rice, ${ }^{1}$ The PILOT Investigators and the Pragmatic Critical Care Research Group
To cite: Semler MW, Casey JD, Lloyd BD, et al. Protocol and statistical analysis plan for the Pragmatic Investigation of optimaL Oxygen Targets (PILOT) clinical trial. BMJ Open 2021;11:e052013. doi:10.1136/ bmjopen-2021-052013

- Prepublication history and additional supplemental material for this paper are available online. To view these files, please visit the journal online (http://dx.doi.org/10.1136/ bmjopen-2021-052013)

Received 05 April 2021 Accepted 12 October 202
Check for updates

(C) Author(s) (or their employer(s)) 2021. Re-use permitted under CC BY-NC. No commercial re-use. See rights and permissions. Published by BMJ.

For numbered affiliations see end of article.

Correspondence to Dr Matthew W Semler; matthew.w.semler@vumc.org

\section{ABSTRACT}

Introduction Mechanical ventilation of intensive care unit (ICU) patients universally involves titration of the fraction of inspired oxygen to maintain arterial oxygen saturation $\left(\mathrm{SpO}_{2}\right)$. However, the optimal $\mathrm{SpO}_{2}$ target remains unknown.

Methods and analysis The Pragmatic Investigation of optimaL 0xygen Targets (PILOT) trial is a prospective, unblinded, pragmatic, cluster-crossover trial being conducted in the emergency department (ED) and medical ICU at Vanderbilt University Medical Center in Nashville, Tennessee, USA. PILOT compares use of a lower $\mathrm{SpO}_{2}$ target (target $90 \%$ and goal range: $88 \%-92 \%$ ), an intermediate $\mathrm{SpO}_{2}$ target (target $94 \%$ and goal range: $92 \%-96 \%$ ) and a higher $\mathrm{SpO}_{2}$ target (target $98 \%$ and goal range: $96 \%-100 \%)$. The study units are assigned to a single $\mathrm{SpO}_{2}$ target (cluster-level allocation) for each 2-month study block, and the assigned $\mathrm{SpO}_{2}$ target switches every 2 months in a randomly generated sequence (cluster-level crossover). The primary outcome is ventilator-free days (VFDs) to study day 28 , defined as the number of days alive and free of invasive mechanical ventilation from the final receipt of invasive mechanical ventilation through 28 days after enrolment.

Ethics and dissemination The trial was approved by the Vanderbilt Institutional Review Board. The results will be submitted for publication in a peer-reviewed journal and presented at one or more scientific conferences.

Trial registration number The trial protocol was registered with ClinicalTrials.gov on 25 May 2018 prior to initiation of patient enrolment (ClinicalTrials.gov identifier: NCT03537937).

\section{INTRODUCTION}

Each year 2-3million intensive care unit (ICU) patients receive invasive mechanical ventilation. ${ }^{1-3}$ Despite recent advances in lung-protective ventilation, ${ }^{4}$ in-hospital mortality among mechanically ventilated ICU patients remains $25 \%-35 \% .^{5}$

Mechanical ventilation for ICU patients universally involves titrating the fraction of

\section{Strengths and limitations of this study}

- This ongoing pragmatic trial will provide information on the optimal oxygen saturation target during invasive mechanical ventilation of critically ill adultsinforming a common therapy in current clinical practice for which there is limited available evidence on which to base care.

- Broad inclusion criteria will increase generalisability and the sample size will allow examination of important patient subgroups.

- The trial is being conducted at a single centre.

- The nature of the study intervention does not allow blinding.

- Decisions regarding oxygen administration before and after invasive mechanical ventilation are deferred to treating clinicians.

inspired oxygen $\left(\mathrm{FiO}_{2}\right)$ to maintain arterial oxygen saturation $\left(\mathrm{SpO}_{2}\right)$ within a goal range. Despite decades of ICU practice, however, the optimal $\mathrm{SpO}_{2}$ target remains unknown. Higher $\mathrm{SpO}_{2}$ targets $(96 \%-100 \%)$ provide a margin of safety against hypoxaemia, but may increase exposure to excess $\mathrm{FiO}_{2}$, hyperoxaemia, and tissue hyperoxia, causing oxidative damage, ${ }^{6-8}$ inflammation $^{9} 10$ and increased alveolar-capillary permeability. ${ }^{11}$ Lower $\mathrm{SpO}_{2}$ targets (88\%-92\%) minimise exposure to excess $\mathrm{FiO}_{2}$, hyperoxaemia and tissue hyperoxia, ${ }^{412} 13$ but may increase the risk of hypoxaemia and tissue hypoxia. ${ }^{14}{ }^{15} \mathrm{An}$ intermediate $\mathrm{SpO}_{2}$ target $(92 \%-96 \%)$ may avoid the risks of both hyperoxia and hypoxia or, conversely, may expose patients intermittently to both sets of risks. ${ }^{16} 17$

The relative risks and benefits of different $\mathrm{SpO}_{2}$ or $\mathrm{PaO}_{2}$ targets have been extensively examined in the setting of the neonatal $\mathrm{ICU}^{18-21}$ and have been examined among 
adult ICU patients in a series of recently published clinical trials. ${ }^{22-27}$ Together, these trials have suggested that both higher and lower oxygenation targets are safe-although some trials have potentially suggested better outcomes with higher targets ${ }^{25}$ and other trials have suggested potentially better outcomes with lower targets. $^{24}$

Given the still incomplete evidence from randomised trials, current guidelines offer divergent recommendations-ranging from tolerating $\mathrm{SpO}_{2}$ values as low as $88 \%{ }^{28-30}$ to pursuing $\mathrm{SpO}_{2}$ values as high as $98 \% .{ }^{31}$ In clinical practice, hyperoxaemia remains common, ${ }^{32} 33$ even among patients cared for by clinicians who self-identify as avoiding high oxygen levels. ${ }^{34}$

The wide variation in current practice, conflicting guidelines and conflicting data from some available trials indicate the need for further clinical trials to determine the effect of $\mathrm{SpO}_{2}$ target on patient outcomes. ${ }^{12}{ }^{35} \mathrm{We}$ designed the Pragmatic Investigation of optimaL Oxygen Targets (PILOT) trial to examine the effects of higher, intermediate and lower $\mathrm{SpO}_{2}$ targets on the number of days alive and free of invasive mechanical ventilation among mechanically ventilated ICU patients.

\section{METHODS AND ANALYSIS}

This manuscript was prepared by the PILOT investigators (online supplemental file 1, section 1) in accordance with Standard Protocol Items: Recommendations for Interventional Trials (SPIRIT) guidelines (figure 1; SPIRIT checklist in online supplemental file 1, section 2). ${ }^{36}$ This manuscript describes key elements of the trial protocol and statistical analysis plan. The supplemental methods in online supplemental file 1 provide additional background on prior trials (section 3), rationale for design decisions (sections 4-5), $\mathrm{SpO}_{2}$ monitoring and management (sections 6-8), institutional protocols for mechanical ventilation (sections 9-17), a complete list of data elements (section 18), definitions of exploratory outcomes and measures of separation between groups (sections 19-21), and details of the interim analysis (section 22) and secondary analyses (sections 23-25).

\section{Study design}

The PILOT trial is a prospective, unblinded, pragmatic, cluster-crossover trial being conducted in the ED and medical ICU at Vanderbilt University Medical Center in Nashville, Tennessee, USA. PILOT compares use of a

\begin{tabular}{|c|c|c|c|c|}
\hline \multirow[b]{3}{*}{ TIMEPOINT } & \multicolumn{4}{|c|}{ STUDY PERIOD } \\
\hline & \multirow{2}{*}{$\begin{array}{c}\begin{array}{c}\text { Allocation and } \\
\text { Enrollment }\end{array} \\
\begin{array}{c}\text { First receipt of } \\
\text { invasive mechanical } \\
\text { ventilation in a } \\
\text { study location }\end{array} \\
\end{array}$} & \multicolumn{2}{|c|}{ On-Study } & \multirow{2}{*}{$\begin{array}{c}\text { Study } \\
\text { Termination } \\
\begin{array}{c}\text { Discharge or } 28 \\
\text { days after } \\
\text { enrolment }\end{array}\end{array}$} \\
\hline & & $\begin{array}{c}\text { Receiving } \\
\text { invasive } \\
\text { mechanical } \\
\text { ventilation in } \\
\text { study location }\end{array}$ & $\begin{array}{l}\text { Hospitalized but } \\
\text { not receiving } \\
\text { invasive } \\
\text { mechanical } \\
\text { ventilation in a } \\
\text { study location } \\
\end{array}$ & \\
\hline \multirow{3}{*}{$\begin{array}{l}\text { ENROLMENT: } \\
\text { Eligibility screen } \\
\text { Allocation }\end{array}$} & $X$ & & & \\
\hline & $X$ & & & \\
\hline & $X$ & & & \\
\hline \multicolumn{5}{|l|}{ INTERVENTIONS: } \\
\hline $\begin{array}{r}\text { Higher SpO2 Target } \\
\text { Titrating FiO2 to SpO2 } 96-100 \%\end{array}$ & $X$ & $X$ & & \\
\hline $\begin{array}{r}\text { Intermediate SpO2 Target } \\
\text { Titrating FiO2 to SpO2 } 92-96 \%\end{array}$ & $X$ & $\mathrm{X}$ & & \\
\hline $\begin{array}{r}\text { Lower SpO2 Target } \\
\text { Titrating FiO2 to SpO2 88-92\% }\end{array}$ & $X$ & $X$ & & \\
\hline $\begin{array}{l}\text { Screening for indications for } \\
\text { SpO2 target modification }\end{array}$ & $X$ & $X$ & & \\
\hline \multicolumn{5}{|l|}{ ASSESSMENTS: } \\
\hline Baseline Variables & $X$ & & & \\
\hline On-study Variables & $X$ & $X$ & $X$ & \\
\hline Clinical Outcomes & & & & $X$ \\
\hline
\end{tabular}

Figure 1 Standard Protocol Items: Recommendations for Interventional Trials checklist. Enrolment, interventions and assessments. $\mathrm{FiO}_{2}$, fraction of inspired oxygen; $\mathrm{SpO}_{2}$, arterial oxygen saturation. 
lower $\mathrm{SpO}_{2}$ target (target $90 \%$ and goal range: $88 \%-92 \%$ ), an intermediate $\mathrm{SpO}_{2}$ target (target $94 \%$ and goal range: 92\%-96\%) and a higher $\mathrm{SpO}_{2}$ target (target $98 \%$ and goal range: $96 \%-100 \%$ ) with regard to the number of days alive and free of invasive mechanical ventilation among mechanically ventilated ICU patients. Consistent with the concept of a pragmatic clinical trial, ${ }^{37}$ the eligibility criteria are broad, the delivery of the intervention is embedded in routine clinical care and executed by clinical personnel, and data collection prioritises clinical outcomes over mechanistic evaluation. The trial was approved by the Vanderbilt University Medical Center Institutional Review Board (IRB 171272). The trial is investigator initiated with funding provided by the National Heart, Lung, and Blood Institute (K23HL143053). The trial protocol was registered with ClinicalTrials.gov on 25 May 2018 prior to initiation of patient enrolment on 1 July 2018 (ClinicalTrials.gov identifier: NCT03537937).

\section{Patient and public involvement}

Materials used to communicate about the study with patients and families were developed with input from the Vanderbilt Community Engaged Research Core and the Vanderbilt Community Advisory Council.

\section{Study site and population}

The trial is being conducted in the adult ED and medical ICU at Vanderbilt University Medical Center.

\section{The inclusion criteria are}

1 . Age $\geq 18$ years.

2. Receiving mechanical ventilation through an endotracheal tube or tracheostomy.

3. Admitted to the study ICU or admission to the study ICU from the ED is planned.

\section{The exclusion criteria are}

1. Known pregnancy or beta-human chorionic gonadotropin level greater than the laboratory upper limit of normal in a patient capable of becoming pregnant (if measured clinically).

2. Known to be a prisoner.

Adults located in the study ICU or for whom admission to the study ICU from the ED is planned who meet inclusion criteria and do not meet exclusion criteria are enrolled immediately on receipt of invasive mechanical ventilation in a study location. The time of enrolment for the trial ('time zero') is the time of first receipt of invasive mechanical ventilation in a participating study location.

\section{Randomisation and treatment allocation}

For each of the 18 2-month blocks during the 36 months of enrolment in the PILOT trial, the medical ICU is assigned to a single $\mathrm{SpO}_{2}$ target (cluster-level allocation). Every 2 months, the ICU will switch between use of a lower $\mathrm{SpO}_{2}$ target (target $90 \%$ and goal range: $88 \%-92 \%$ ), use of an intermediate $\mathrm{SpO}_{2}$ target (target 94\% and goal range: $92 \%-96 \%$ ) and use of a higher $\mathrm{SpO}_{2}$ target (target $98 \%$ and goal range: $96 \%-100 \%$ ) in a randomly generated sequence (cluster-level crossover) (figure 2). The order of study group assignments for each 2-month block was generated by computerised randomisation using permuted blocks of three to minimise the impact of seasonal variation and temporal changes. For the 36 months of enrolment in the PILOT trial, patients receiving invasive mechanical ventilation in the $\mathrm{ED}$ for whom admission to the medical ICU is planned will receive the same $\mathrm{SpO}_{2}$ target assigned to the medical ICU. The study did not enrol in April and May of 2020 due to disruptions in research and clinical care from the COVID-19 pandemic (figure 2).

\section{Washout periods}

The last 7 days of each 2-month block are considered an analytic washout period during which the ICU continues to target the assigned $\mathrm{SpO}_{2}$, but data from new patients are not included in the primary analysis. Assuming a median duration of mechanical ventilation of 3 (IQR: 3-5) days, a 7-day washout period will ensure that $98 \%$ patients in the primary analysis do not experience a 'crossover' from a period assigned to one assigned $\mathrm{SpO}_{2}$ target to a period assigned to another $\mathrm{SpO}_{2}$ target. Data from patients admitted during washout periods will be included in a prespecified sensitivity analysis (see Statistical analysis section). Any patient who does remain mechanically ventilated in the study ICU through a crossover from a period assigned to one $\mathrm{SpO}_{2}$ target to a period assigned to another $\mathrm{SpO}_{2}$ target will be analysed in the $\mathrm{SpO}_{2}$ target group to which the ICU was assigned at the time of the patient's enrolment in the trial (intentionto-treat analysis).

\begin{tabular}{|c|c|c|c|c|c|c|c|c|c|c|c|c|c|c|c|c|c|}
\hline \multicolumn{6}{|c|}{ Study Year 1} & \multicolumn{6}{|c|}{ Study Year 2} & \multicolumn{6}{|c|}{ Study Year 3} \\
\hline $\begin{array}{l}\text { Jul- } \\
\text { Aug }\end{array}$ & $\begin{array}{l}\text { Sep- } \\
\text { Oct }\end{array}$ & $\begin{array}{l}\text { Nov- } \\
\text { Dec }\end{array}$ & $\begin{array}{l}\text { Jan- } \\
\text { Feb }\end{array}$ & $\begin{array}{c}\text { Mar- } \\
\text { Apr }\end{array}$ & $\begin{array}{l}\text { May- } \\
\text { Jun }\end{array}$ & $\begin{array}{l}\text { Jul- } \\
\text { Aug }\end{array}$ & $\begin{array}{l}\text { Sep- } \\
\text { Oct }\end{array}$ & $\begin{array}{l}\text { Nov- } \\
\text { Dec }\end{array}$ & $\begin{array}{l}\text { Jan- } \\
\text { Feb }\end{array}$ & $\begin{array}{l}\text { Mar } \\
\text { \& Jun }\end{array}$ & $\begin{array}{l}\text { Jul- } \\
\text { Aug }\end{array}$ & $\begin{array}{l}\text { Sept- } \\
\text { Oct }\end{array}$ & $\begin{array}{l}\text { Nov- } \\
\text { Dec }\end{array}$ & $\begin{array}{l}\text { Jan- } \\
\text { Feb }\end{array}$ & $\begin{array}{c}\text { Mar- } \\
\text { Apr }\end{array}$ & $\begin{array}{l}\text { May- } \\
\text { Jun }\end{array}$ & $\begin{array}{l}\text { Jul- } \\
\text { Aug }\end{array}$ \\
\hline \multicolumn{3}{|c|}{2018} & \multicolumn{6}{|c|}{2019} & \multicolumn{5}{|c|}{2020} & \multicolumn{4}{|c|}{2021} \\
\hline A & B & C & B & C & A & C & B & A & A & B & C & B & A & C & B & A & C \\
\hline
\end{tabular}

Figure 2 Group assignment during the trial. For each of the 18 2-month study periods, the study intensive care unit is randomly assigned to a higher, intermediate or lower $\mathrm{SpO}_{2}$ target. in this figure, The letters ' $\mathrm{A}$ ', ' $\mathrm{B}$ ' and ' $\mathrm{C}$ ' each correspond to one of the three possible $\mathrm{SpO}_{2}$ targets, the allocation sequence of which remains concealed until the start of each 2-month study period. The study did not enrol in April and May of 2020 due to disruptions in research and clinical care from the COVID-19 pandemic. As a result, March and June of 2020 represent a single 2-month block assigned to one $\mathrm{SpO}_{2}$ target. $\mathrm{SpO}_{2}$, arterial oxygen saturation. 
Table $1 \mathrm{SpO}_{2}$ and $\mathrm{PaO}_{2}$ targets and goal ranges by study group

\begin{tabular}{lllcc}
\hline Study group & $\mathbf{S p O}_{2}$ target & $\mathbf{S p O}_{2}$ goal range & $\begin{array}{l}\mathbf{P a O}_{2} \text { target } \mathbf{( m m} \\
\mathbf{H g})\end{array}$ & $\begin{array}{l}\mathbf{P a O}_{2} \mathbf{g o a l ~ r a n g e} \\
\mathbf{( m m} \mathbf{H g})\end{array}$ \\
\hline Lower $\mathrm{SpO}_{2}$ target & $90 \%$ & $88 \%-92 \%$ & 60 & $55-65$ \\
Intermediate $\mathrm{SpO}_{2}$ target & $94 \%$ & $92 \%-96 \%$ & 70 & $65-8$ \\
Higher $\mathrm{SpO}_{2}$ target & $98 \%$ & $96 \%-100 \%$ & 110 & $>80$ \\
\hline
\end{tabular}

For each study group, the $\mathrm{SpO}_{2}$ target and goal range are displayed. $\mathrm{PaO}_{2}$ is used to guide titration of $\mathrm{FiO}_{2}$ for participants without reliable pulse oximetry monitoring.

$\mathrm{FiO}_{2}$, fraction of inspired oxygen; $\mathrm{PaO}_{2}$, arterial oxygen tension; $\mathrm{SpO}_{2}$, arterial oxygen saturation.

\section{Study interventions}

\section{Choice of $\mathrm{SpO}_{2}$ targets}

In clinical practice, $98 \%$ of $\mathrm{SpO}_{2}$ values experienced by mechanically ventilated adults fall between $88 \%$ and $100 \% .^{32} 33$ Within this range, current guidelines for oxygen therapy in mechanically ventilated adults outline three contrasting approaches: (1) allowing the lower end of the range of acceptable $\mathrm{SpO}_{2}$ values to be as low as $88 \%^{28} 29$ to avoid excess $\mathrm{FiO}_{2}$, hyperoxaemia and hyperoxia; (2) titrating within an intermediate range of $\mathrm{SpO}_{2}$ values, such as $92 \%-96 \%$; or (3) targeting higher $\mathrm{SpO}_{2}$ to avoid the risks of hypoxaemia and hypoxia. ${ }^{31}$ The PILOT trial has three study groups, each emulating a different approach to $\mathrm{SpO}_{2}$ targets represented in guidelines and clinical practice (table 1$)$.

\section{Oxygen titration}

In the study ED and ICU, titration of $\mathrm{FiO}_{2}$ to maintain $\mathrm{SpO}_{2}$ for mechanically ventilated adults is typically performed by respiratory therapists with input from nurses and physicians. In preparation for the PILOT trial, we collaborated with respiratory therapy leaders in the study ED and ICU to adapt existing ventilator management protocols to provide guidance for respiratory therapists in titrating $\mathrm{FiO}_{2}$ to achieve each of the three study $\mathrm{SpO}_{2}$ targets.

For patients enrolled in the study, respiratory therapists are instructed to begin titrating $\mathrm{FiO}_{2}$ to the target $\mathrm{SpO}_{2}$ value within $15 \mathrm{~min}$ of the initiation of mechanical ventilation. During the maintenance of invasive mechanical ventilation, $\mathrm{SpO}_{2}$ is assessed by continuous pulse oximetry. The protocol directs the respiratory therapist managing the patient's ventilator to target an $\mathrm{SpO}_{2}$ value of $90 \%$ in the lower $\mathrm{SpO}_{2}$ target group, an $\mathrm{SpO}_{2}$ value of $94 \%$ in the intermediate $\mathrm{SpO}_{2}$ target group and an $\mathrm{SpO}_{2}$ value of $98 \%$ in the higher $\mathrm{SpO}_{2}$ target group (table 1). Respiratory therapists and other treating clinicians titrate $\mathrm{FiO}_{2}$ when the $\mathrm{SpO}_{2}$ is out of the goal range, when the $\mathrm{SpO}_{2}$ is within the goal range but closer alignment with the assigned $\mathrm{SpO}_{2}$ target is desired, to facilitate weaning from mechanical ventilation, or for other clinical indications. $\mathrm{SpO}_{2}$ is reassessed 5 min after each change in $\mathrm{FiO}_{2}$ or sooner if clinically indicated.

The protocol determines the $\mathrm{SpO}_{2}$ target from enrolment until the first of: (1) discontinuation of invasive mechanical ventilation, (2) transfer out of a participating study location, (3) completion of an $\mathrm{SpO}_{2}$ target modification sheet by treating clinicians or (4) end of the 2-month study period. The protocol does not determine the $\mathrm{SpO}_{2}$ target during time periods in which the patient is not physically located in a study location (eg, during transport) or when $\mathrm{FiO}_{2}$ is being administered for purposes other than achieving a target $\mathrm{SpO}_{2}\left(\mathrm{eg}\right.$, when an $\mathrm{FiO}_{2}$ of 1.0 is being administered for a procedure).

At any time, if a treating clinician or a patient, family member or surrogate feels that an $\mathrm{SpO}_{2}$ target other than that assigned by the study would be best for the optimal treatment of the patient for any reason, the $\mathrm{SpO}_{2}$ target for that patient is modified. To modify the target, the respiratory therapist and supervising physician complete a one-page $\mathrm{SpO}_{2}$ target modification sheet documenting the new $\mathrm{SpO}_{2}$ target and the rationale for modifying the target. Examples of conditions for which the assigned $\mathrm{SpO}_{2}$ target may be modified that were specified in the initial trial protocol included pneumothorax, pneumomediastinum, carbon monoxide poisoning, decompression sickness, bleomycin toxicity and paraquat toxicity. Examples of conditions for which the assigned $\mathrm{SpO}_{2}$ target may be modified that were not explicitly specified in the initial trial protocol include severe chronic obstructive pulmonary disease, severe acute respiratory distress syndrome, severe anaemia, status post lung transplantation and receipt of extracorporeal membrane oxygenation support. Trial protocol directs only the titration of $\mathrm{FiO}_{2}$ to the assigned $\mathrm{SpO}_{2}$ target. Other aspects of invasive mechanical ventilation, such as tidal volume, ${ }^{4}$ positive end-expiratory pressure ${ }^{39}$ and use of rescue therapies for hypoxaemia, are determined by institutional protocols and treating clinicians (see sections 9-17 of online supplemental file 1).

\section{Blinding}

Similar to prior studies of $\mathrm{SpO}_{2}$ targets among critically ill adults, ${ }^{2426}$ patients and clinicians will not be blinded to study group assignment.

\section{Data collection}

The PILOT trial uses data collected by two methods to minimise observer bias: (1) manual data collection by study personnel and (2) automated collection of structured data recorded in routine clinical care, exported daily from the institution's electronic health record and 
patient registration, billing and laboratory clinical information systems into an Enterprise Data Warehouse. We have previously validated the quality of the automated method of data collection against the reference standard of two-physician manual chart review ${ }^{41}$ and have employed this approach for the conduct of prior pragmatic trials. ${ }^{42} 43$ Data are stored, curated and secured in REDCap. $^{44}$

\section{Outcomes}

Primary outcome

The primary outcome is VFDs to study day 28. VFDs will be defined as the number of whole calendar days alive and free of invasive mechanical ventilation beginning at midnight on the day of the final receipt of invasive mechanical ventilation through day 28 after enrolment. ${ }^{45}{ }^{46}$ Outcome ascertainment will cease at the time of hospital discharge or 28 days after enrolment, whichever occurs first. Receipt of invasive mechanical ventilation will be considered to end when patients undergo the final tracheal extubation or disconnection of the ventilator from the endotracheal tube or tracheostomy tube between enrolment and 28 days after enrolment. Patients whose final receipt of invasive mechanical ventilation occurs on the day of enrolment will receive 27 VFDs. Patients who continue to receive invasive mechanical ventilation 28 days after enrolment will receive 0 VFDs. Patients who die prior to day 28 will receive 0 VFDs. Patients who are discharged from the hospital prior to day 28 and are receiving invasive mechanical ventilation at the time of discharge will receive 0 VFDs. Patients who are removed from invasive mechanical ventilation and are discharged from the hospital without invasive mechanical ventilation prior to 28 days will be assumed to remain free of invasive mechanical ventilation between hospital discharge and day 28. For patients who are removed from invasive mechanical ventilation, return to invasive mechanical ventilation, and are subsequently removed again from invasive mechanical ventilation prior to day 28 , VFDs will be counted from the final receipt of invasive mechanical ventilation prior to day 28 .

\section{Secondary outcome}

The sole prespecified secondary outcome is 28-day in-hospital mortality, defined as death from any cause between enrolment and the first of hospital discharge or 28 days after enrollment.

\section{Exploratory clinical outcomes}

1. ICU mortality - death in the ICU between enrolment and the first of 28 days after enrolment or hospital discharge

2. Free-day outcomes-defined as whole calendar days from last receipt of therapy until 28 days (online supplemental file 1, section 19)

i. Vasopressor-free days

ii. Renal replacement therapy-free days

iii. ICU-free days iv. Hospital-free days

Exploratory organ function outcomes

1. Daily non-respiratory Sequential Organ Failure Assessment (SOFA) score (online supplemental table $\mathrm{S} 1)^{47}$

2. Plasma creatinine concentration $(\mathrm{mg} / \mathrm{dL})$

3. Plasma lactate concentration $(\mathrm{mmol} / \mathrm{L})$

4. Presence of acute respiratory distress syndrome by Berlin criteria ${ }^{48}$

5. Stage II or greater acute kidney injury (AKI) by Kidney Disease: Improving Global Outcomes creatinine criteria. $^{49}$

\section{Exploratory safety outcomes}

1. Atrial arrhythmia

2. Ventricular arrhythmia

3. Cardiac arrest with return of spontaneous circulation

4. Pneumothorax or pneumomediastinum

5. Ischaemic stroke

6. Myocardial infarction ${ }^{50}$

\section{Additional long-term patientimportant outcomes}

The independently funded Cognitive Outcomes in the Pragmatic Investigation of Optimal Oxygen Targets (CO-PILOT) study (R21AG063126) will assess cognitive, physical and psychological outcomes at 12 months after enrolment in the PILOT trial. The protocol and statistical analysis plan for the CO-PILOT study will be published separately.

\section{Statistical analysis and reporting}

Sample size estimation and power calculation

In a prior cluster-randomised cluster-crossover trial in the same ICU, ${ }^{51} 880$ mechanically ventilated adults were enrolled per year (73.3 per month), with a median of 22 VFDs (IQR: 0-25 VFDs) and an intracluster intraperiod correlation of 0.01 . We estimate 2640 mechanically ventilated adults will be admitted to the study ICU during the 36-month PILOT trial, of whom 390 will be excluded from the primary analysis for initial receipt of invasive mechanical ventilation in a study location during a washout period and 2250 will be enrolled and included in the primary analysis. With a total enrolment of 2250 patients, a SD in the primary outcome of VFDs of 11.4 days, and a two-sided alpha of 0.05 , we calculated using a t-test that the PILOT trial will have $92 \%$ statistical power to detect an absolute reduction in VFDs of 2.0 days (similar to the numerical difference in VFDs between $\mathrm{SpO}_{2}$ target groups reported in prior studies ${ }^{22}{ }^{24}$ ).

\section{DSMB and interim analysis}

An independent Data and Safety Monitoring Board (DSMB) oversees the trial. On 23 March 2020 the DSMB conducted a single, planned interim analysis at the anticipated halfway point of the trial and recommended the trial to continue without modification (see DSMB charter in online supplemental file 2) and details of interim analysis in online supplemental file 1 , section 22). The 
DSMB is composed of two physicians outside the study institution with expertise in adult pulmonary and critical care medicine clinical practice and clinical research, one bioethicist and one biostatistician.

\section{Statistical analysis principles}

R (R Foundation for Statistical Computing, Vienna, Austria) will be used for analyses. Analyses will be conducted at the level of an individual patient during an individual hospitalisation in an intent-to-treat fashion, unless otherwise specified. Continuous variables will be reported as mean $\pm \mathrm{SD}$ or median and $\mathrm{IQR}$; categorical variables will be reported as frequencies and proportions.

\section{Main analysis of the primary outcome}

The main analysis will be an intention-to-treat comparison of the primary outcome of VFDs between the higher, intermediate and lower $\mathrm{SpO}_{2}$ target groups among all patients enrolled in the trial except ${ }^{1}$ those admitted during one of the 7-day washout periods and ${ }^{2}$ those with a laboratory-confirmed diagnosis of COVID-19. Patients with a diagnosis of COVID-19 will be excluded from the main analysis for two reasons. First, the majority of the PILOT trial occurred prior the COVID-19 pandemic, with too few 2-month study blocks occurring during the pandemic to ensure balance in the number of patients with COVID-19 between trial groups. Second, at the study hospital, ICU patients diagnosed with COVID-19 are transferred to a separate, dedicated COVID-19 ICU that was not participating in the PILOT trial. Thus, patients with COVID-19 are unlikely to have received significant exposure to the $\mathrm{SpO}_{2}$ target intervention in the PILOT trial. Patients enrolled during washout periods and patients diagnosed with COVID-19 will be included in sensitivity analyses (see Sensitivity analyses below).

It is possible to estimate a conditional effect, which is interpreted as the effect of a given $\mathrm{SpO}_{2}$ target on an individual patient given the values of the covariates for that patient, or a marginal effect, which is interpreted as the population effect of implementing a given $\mathrm{SpO}_{2}$ target as a general policy. ${ }^{52}$ Since an $\mathrm{SpO}_{2}$ target intervention may be applied both at the patient level as an individual intervention and at the unit level as a general policy, both may be of interest.

To estimate the conditional effect, we will use a proportional odds model with independent covariates of group assignment (higher, intermediate or lower $\mathrm{SpO}_{2}$ target) and time. ${ }^{5354}$ Time (in days) will be treated as a continuous variable with values ranging from 1 (first day of enrolment) to 1097 (final day of enrolment) and will be analysed using restricted cubic splines with multiple knots to allow for non-linearity resulting from seasonality or secular trends. For the purposes of declaring a statistically significant difference between groups in the primary endpoint, we will consider the conditional effect from the proportional odds model and a two-sided $\mathrm{p}$ value of 0.05 .

To estimate the marginal effect, we will use generalised estimating equations with study period as the cluster and an independent variable for group assignment (higher, intermediate or lower $\mathrm{SpO}_{2}$ target).

For both approaches, in addition to assessing for an overall group effect within the model, we will estimate the differences between each pair of $\mathrm{SpO}_{2}$ targets by extracting $95 \%$ CIs from the model.

\section{Sensitivity analyses of the primary outcome}

- We will repeat the primary analysis using alternative statistical approaches to comparing the VFDs outcome between groups such as zero-inflated Poisson regression or zero-inflated negative binomial regression, global rank scale analysis ${ }^{55}$ and Fine and Gray competing risk regression.

- We will repeat the primary analysis with adjustment for prespecified baseline covariates of age, sex, race and ethnicity, source of ICU admission, vasopressor receipt, acute diagnoses at enrolment, and severity of illness as assessed by the non-respiratory SOFA score.

- We will repeat the primary analysis replacing the continuous covariate of time with a categorical covariate of season defined as: winter (January, February, March); spring (April, May, June); summer (July, August, September); and fall (October, November, December).

- We will repeat the primary analysis among all patients enrolled in the trial, including ${ }^{1}$ patients initiated on invasive mechanical ventilation in a study location during one of the prespecified 7-day washout periods $\mathrm{and}^{2}$ patients with a diagnosis of COVID-19.

\section{Analysis of effect modification for the primary outcome}

We will examine whether prespecified baseline variables modify the effect of study group on the primary outcome using formal tests of statistical interaction in a proportional odds model. Independent variables will include study group assignment, the potential effect modifier of interest and the interaction between the two (eg, study group $\times$ presence of sepsis or septic shock) and time. Significance will be determined by the $\mathrm{p}$ value for the interaction term, with values $<0.10$ considered to suggest a potential interaction and values $<0.05$ considered to confirm an interaction.

We will examine whether the following baseline variables modify the effect of study group on the primary outcome:

1. Age;

2. Race and ethnicity (Hispanic, non-Hispanic Black, non-Hispanic white, Other);

3. Source of admission to the ICU (ED, hospital ward, another ICU in the study hospital, operating room, outside hospital);

4. Duration of invasive mechanical ventilation prior to enrollment;

5. Chronic comorbidities (categories are not mutually exclusive)

i. Receipt of supplemental oxygen at place of residence prior to hospital admission (yes, no); 
ii. Coronary artery disease or heart failure with reduced ejection fraction (yes, no);

6. Acute diagnoses at enrollment (categories are not mutually exclusive $)^{56}$

i. cardiac arrest (yes, no);

ii. acute myocardial infarction (yes, no);

iii. sepsis or septic shock (yes, no);

iv. acute respiratory distress syndrome (yes, no);

7. Receipt of vasopressors at enrollment (yes, no);

8. Non-respiratory SOFA score at enrollment;

9. Time period before the COVID-19 pandemic (July 2018 to December 2019), and during the COVID-19 pandemic (January 2020 to August 2021).

\section{Analysis of the secondary outcome}

The sole prespecified secondary outcome of 28-day in-hospital mortality will be compared between the three study groups in an intention-to-treat fashion in the main analysis population using a logistic regression model with independent covariates of group assignment (higher, intermediate or lower $\mathrm{SpO}_{2}$ target) and time. In addition to assessing for an overall group effect within the model, we will estimate the differences between each pair of $\mathrm{SpO}_{2}$ targets by extracting $95 \%$ CIs from the model.

\section{Analysis of the exploratory outcomes}

Each of the exploratory outcomes will be compared between groups in an intention-to-treat fashion in the main analysis population. Exploratory outcomes will be compared between study groups in a similar manner as for primary and secondary outcomes. A logistic model will be used for binary outcomes, a multinomial model for categorical outcomes, and a proportional odds model will be used for ordinal and continuous outcomes.

\section{Trial status}

PILOT is an ongoing pragmatic trial comparing higher, intermediate and lower $\mathrm{SpO}_{2}$ targets for mechanically ventilated critically ill adults. Patient enrolment began on 1 July 2018 and is anticipated to conclude on 31 August 2021.

\section{Ethics and dissemination}

\section{IRB approval}

The trial was approved by the IRB of Vanderbilt University Medical Center with a waiver of informed consent (IRB\# 171272), details of which are provided in (online supplemental file 1, section 26). Participants who regain capacity to provide informed consent, or legally authorised surrogate decision-makers for those patients who do not regain the capacity to provide informed consent, are approached to provide informed consent for assessment of long-term outcomes as a part of the independently funded CO-PILOT study (R21AG063126).

\section{Information for patients and families}

An information sheet providing an IRB approved lay language summary of the study and containing the contact information for investigators (who remain available throughout the study period to provide additional information to patients and families on request) is made available throughout the study period in glass display cases near the public entrance to the ICU and near the centre of the ICU, in the 'welcome packet' of information about the ICU, which is distributed at the time of ICU admission to patients, families and surrogates by the medical receptionist or charge nurse as a part of routine admission processes, in a brochure holder in the family waiting room for the study ICU, and by treating physicians and respiratory therapist to any patients, families, or surrogates with questions or concerns about the study.

\section{Protocol changes}

Any changes to the trial protocol will be recorded on ClinicalTrials.Gov as per SPIRIT guidelines (see section 27 of online supplemental file 1).

\section{Data handling and sharing}

For details of privacy, data handling and data sharing, see sections 28-29 of online supplemental file 1 .

\section{Dissemination plan}

Trial results will be submitted to a peer-reviewed journal for consideration of publication and will be presented at scientific conferences. The results of the study will be disseminated to patients and the public at the completion of the trial.

The full list of the PILOT investigators may be found in (online supplemental file 1, section 1).

\section{Author affiliations}

${ }^{1}$ Department of Medicine, Division of Allergy, Pulmonary and Critical Care Medicine, Vanderbilt University School of Medicine, Nashville, Tennessee, USA

${ }^{2}$ Division of Respiratory Care, Vanderbilt University Medical Center, Nashville, Tennessee, USA

${ }^{3}$ Department of Pharmaceutical Services, Vanderbilt University Medical Center, Nashville, Tennessee, USA

${ }^{4}$ Department of Medicine, Vanderbilt University Medical Center, Nashville, Tennessee, USA

${ }^{5}$ Department of Biostatistics, Vanderbilt University Schoool of Medicine, Nashville, TN, USA

${ }^{6}$ Department of Anesthesiology, Vanderbilt University Medical Center, Nashville, Tennessee, USA

${ }^{7}$ Department of Emergency Medicine, Vanderbilt University Medical Center, Nashville, Tennessee, USA

\section{Twitter Bradley D. Lloyd @BradLloydVFL}

Collaborators PILOT Investigators Department of Anesthesiology - Robert E Freundlich*, Jonathan P Wanderer* Department of Biostatistics - Christopher J Lindsell ${ }^{\star}$, Li Wang* Department of Emergency Medicine - Jin H Han, Wesley H Self* Department of Internal Medicine - John H Brems ${ }^{*}$, Kevin G Buell* Department of Pharmaceutical Services - Sneha Patel, Joanna L Stollings *Division of Allergy, Pulmonary, and Critical Care Medicine - Gordon R. Bernard*, Jonathan D Casey*, Christina Cleveland, Margaret A Hays*, Luis E Huerta, Karen Jackson, Todd W Rice $^{\star}$, Megan Roth ${ }^{\star}$, Matthew W Semler* Division of Respiratory Care - Pamela G Hastings ${ }^{\star}$, Bradley D Lloyd ${ }^{\star}$, Roger K Richardson, J Craig Rooks All at Vanderbilt University Medical Center in Nashville, Tennessee. Asterisk $\left(^{*}\right)$ denotes members of the writing committee.

Contributors Study concept and design was done by MWS, JDC, CJL, GB, WHS and TWR. Drafting of the manuscript was done by MWS, LW and CJL. Critical revision of the manuscript for important intellectual content was performd by MWS, JDC, BDL, PH, MH, MR, JS, JB, KGB, LW, CJL, RF, JPW, GB, WHS and TWR. LW and 
CJL were responsible for statistical analysis. Study supervision was done by GB, WHS and TWR.

Funding This study was supported in part by a grant from the National Heart Lung and Blood Institute (K23HL143053). JDC was supported in part by the NIH (K23HL153584). REF was supported in part by the NIH (1KL2TR002245, 1K23HL148640). TWR was supported in part by the NIH (U01HL123033, UL1TR002244). Data collection used the Research Electronic Data Capture (REDCap) tool developed and maintained with Vanderbilt Institute for Clinical and Translational Research grant support (UL1 TR000445 from the National CenterCentre for Advancing Translational Sciences). The funding institutions had no role in (1) conception, design or conduct of the study, (2) collection, management, analysis, interpretation or presentation of the data or (3) preparation, review or approval of the manuscript.

Competing interests All authors completed and submitted the ICMJE Form for Disclosure of Potential Conflicts of Interest. RF reported receiving grant funding and consulting fees from Medtronic and stock from 3M outside the current work. TWR reported receiving consulting fees from Cumberland Pharmaceuticals outside the current work. The authors declared no potential conflicts of interest with the current work.

\section{Patient consent for publication Not applicable.}

Provenance and peer review Not commissioned; externally peer reviewed.

Supplemental material This content has been supplied by the author(s). It has not been vetted by BMJ Publishing Group Limited (BMJ) and may not have been peer-reviewed. Any opinions or recommendations discussed are solely those of the author(s) and are not endorsed by BMJ. BMJ disclaims all liability and responsibility arising from any reliance placed on the content. Where the content includes any translated material, BMJ does not warrant the accuracy and reliability of the translations (including but not limited to local regulations, clinical guidelines, terminology, drug names and drug dosages), and is not responsible for any error and/or omissions arising from translation and adaptation or otherwise.

Open access This is an open access article distributed in accordance with the Creative Commons Attribution Non Commercial (CC BY-NC 4.0) license, which permits others to distribute, remix, adapt, build upon this work non-commercially, and license their derivative works on different terms, provided the original work is properly cited, appropriate credit is given, any changes made indicated, and the use is non-commercial. See: http://creativecommons.org/licenses/by-nc/4.0/.

\section{ORCID iD}

Matthew W Semler http://orcid.org/0000-0002-7664-8263

\section{REFERENCES}

1 Wunsch $\mathrm{H}$, Linde-Zwirble WT, Angus DC, et al. The epidemiology of mechanical ventilation use in the United States. Crit Care Med 2010;38:1947-53.

2 Wunsch $\mathrm{H}$, Angus DC, Harrison DA, et al. Comparison of medical admissions to intensive care units in the United States and United Kingdom. Am J Respir Crit Care Med 2011;183:1666-73.

3 Adhikari NKJ, Fowler RA, Bhagwanjee S, et al. Critical care and the global burden of critical illness in adults. Lancet 2010;376:1339-46.

4 , Brower RG, Matthay MA, et al, Acute Respiratory Distress Syndrome Network. Ventilation with lower tidal volumes as compared with traditional tidal volumes for acute lung injury and the acute respiratory distress syndrome. N Engl J Med 2000;342:1301-8.

5 Esteban A, Frutos-Vivar F, Muriel A, et al. Evolution of mortality over time in patients receiving mechanical ventilation. Am J Respir Crit Care Med 2013;188:220-30.

6 Fridovich I. Oxygen toxicity: a radical explanation. J Exp Biol 1998;201:1203-9.

7 Heffner JE, Repine JE. Pulmonary strategies of antioxidant defense. Am Rev Respir Dis 1989;140:531-54.

8 Freeman BA, Crapo JD. Hyperoxia increases oxygen radical production in rat lungs and lung mitochondria. $J$ Biol Chem 1981;256:10986-92.

9 Waxman AB, Einarsson O, Seres T, et al. Targeted lung expression of interleukin-11 enhances murine tolerance of $100 \%$ oxygen and diminishes hyperoxia-induced DNA fragmentation. $J$ Clin Invest 1998;101:1970-82.

10 Griffith DE, Garcia JG, James HL, et al. Hyperoxic exposure in humans. Effects of 50 percent oxygen on alveolar macrophage leukotriene B4 synthesis. Chest 1992;101:392-7.
11 Davis WB, Rennard SI, Bitterman PB, et al. Pulmonary oxygen toxicity. early reversible changes in human alveolar structures induced by hyperoxia. N Engl J Med 1983;309:878-83.

12 Aggarwal NR, Brower RG. Targeting normoxemia in acute respiratory distress syndrome may cause worse short-term outcomes because of oxygen toxicity. Ann Am Thorac Soc 2014:11:1449-53.

13 Meade MO, Cook DJ, Guyatt GH, et al. Ventilation strategy using low tidal volumes, recruitment maneuvers, and high positive end-expiratory pressure for acute lung injury and acute respiratory distress syndrome: a randomized controlled trial. JAMA 2008;299:637-45.

14 Eastwood G, Bellomo R, Bailey M, et al. Arterial oxygen tension and mortality in mechanically ventilated patients. Intensive Care Med 2012;38:91-8.

15 de Jonge E, Peelen L, Keijzers PJ, et al. Association between administered oxygen, arterial partial oxygen pressure and mortality in mechanically ventilated intensive care unit patients. Crit Care 2008;12:R156.

16 Allen BS, Ilbawi MN. Hypoxia, reoxygenation and the role of systemic leukodepletion in pediatric heart surgery. Perfusion 2001;16 Suppl:19-29.

17 Allen BS. The reoxygenation injury: is it clinically important? J Thorac Cardiovasc Surg 2002;124:16-19.

18 Supplemental therapeutic oxygen for prethreshold retinopathy of prematurity (STOP-ROP), a randomized, controlled trial. I: primary outcomes. Pediatrics 2000;105:295-310.

19 SUPPORT Study Group of the Eunice Kennedy Shriver NICHD Neonatal Research Network, Carlo WA, Finer NN, et al. Target ranges of oxygen saturation in extremely preterm infants. $N$ Engl J Med 2010;362:1959-69.

20 Schmidt B, Whyte RK, Asztalos EV, et al. Effects of targeting higher vs lower arterial oxygen saturations on death or disability in extremely preterm infants: a randomized clinical trial. JAMA 2013;309:2111-20.

21 BOOST II United Kingdom Collaborative Group, BOOST II Australia Collaborative Group, BOOST II New Zealand Collaborative Group, et al. Oxygen saturation and outcomes in preterm infants. $N$ Engl $J$ Med 2013:368:2094-104.

22 Panwar R, Hardie M, Bellomo R, et al. Conservative versus liberal oxygenation targets for mechanically ventilated patients. a pilot multicenter randomized controlled trial. Am J Respir Crit Care Med 2016;193:43-51.

23 Asfar P, Schortgen F, Boisramé-Helms J, et al. Hyperoxia and hypertonic saline in patients with septic shock (HYPERS2S): a twoby-two factorial, multicentre, randomised, clinical trial. Lancet Respir Med 2017;5:180-90.

24 Girardis M, Busani S, Damiani E, et al. Effect of conservative vs conventional oxygen therapy on mortality among patients in an intensive care unit: the oxygen-ICU randomized clinical trial. JAMA 2016;316:1583-9.

25 Barrot L, Asfar P, Mauny F, et al. Liberal or conservative oxygen therapy for acute respiratory distress syndrome. N Engl J Med 2020;382:999-1008.

26 ICU-ROX Investigators and the Australian and New Zealand Intensive Care Society Clinical Trials Group, Mackle D, Bellomo R, et al. Conservative oxygen therapy during mechanical ventilation in the ICU. N Engl J Med 2020;382:989-998.

27 Schjørring OL, Klitgaard TL, Perner A, et al. Lower or higher oxygenation targets for acute hypoxemic respiratory failure. $N$ Engl $J$ Med Overseas Ed 2021;384:1301-11.

28 Siemieniuk RAC, Chu DK, Kim LH-Y, et al. Oxygen therapy for acutely ill medical patients: a clinical practice guideline. BMJ 2018;363:k4169.

29 National Heart, Lung, and Blood Institute Acute Respiratory Distress Syndrome (ARDS) Clinical Trials Network, Rice TW, Wheeler AP, et al. Initial trophic vs full enteral feeding in patients with acute lung injury: the EDEN randomized trial. JAMA 2012;307:795-803.

30 Rice TW, Wheeler AP, Thompson BT, et al. Enteral omega-3 fatty acid, gamma-linolenic acid, and antioxidant supplementation in acute lung injury. JAMA 2011;306:1574-81.

31 O'Driscoll BR, Howard LS, Earis J, et al. Bts guideline for oxygen use in adults in healthcare and emergency settings. Thorax 2017;72:ii1-90.

32 Panwar R, Capellier G, Schmutz N, et al. Current oxygenation practice in ventilated patients-an observational cohort study. Anaesth Intensive Care 2013;41:505-14.

33 Suzuki S, Eastwood GM, Peck L, et al. Current oxygen management in mechanically ventilated patients: a prospective observational cohort study. J Crit Care 2013;28:647-54. 
34 Helmerhorst HJ, Schultz MJ, van der Voort PH, et al. Self-reported attitudes versus actual practice of oxygen therapy by ICU physicians and nurses. Ann Intensive Care 2014;4:23

35 Self WH, Semler MW, Rice TW. Oxygen targets for patients who are critically ill: emerging data and state of equipoise. Chest 2020;157:487-8.

36 SPIRIT. Explanation and elaboration: guidance for protocols of clinical trials. - PubMed - NCBI, 2013. Available: https://www.ncbi. nlm.nih.gov/pubmed/23303884 [Accessed 08 Jan 2018].

37 Ware $\mathrm{JH}$, Hamel MB. Pragmatic trials--guides to better patient care? N Engl J Med 2011;364:1685-7.

38 Beasley R, Chien J, Douglas J, et al. Thoracic society of Australia and New Zealand oxygen guidelines for acute oxygen use in adults: 'swimming between the flags'. Respirology 2015;20:1182-91.

39 Brower RG, Lanken PN, Maclntyre N, et al. Higher versus lower positive end-expiratory pressures in patients with the acute respiratory distress syndrome. N Engl J Med 2004;351:327-36.

40 Briel M, Meade M, Mercat A, et al. Higher vs lower positive endexpiratory pressure in patients with acute lung injury and acute respiratory distress syndrome: systematic review and meta-analysis. JAMA 2010;303:865-73

41 Semler MW, Rice TW, Shaw AD, et al. Identification of major adverse kidney events within the electronic health record. J Med Syst 2016;40:167.

42 Semler MW, Noto MJ, Stollings J. Effect of saline versus balanced crystalloids on major adverse kidney events in the medical intensive care unit: the salt randomized trial. Am J Respir Crit Care Med 2016;193:A4290.

43 Semler MW, Self WH, Wang L, et al. Balanced crystalloids versus saline in the intensive care unit: study protocol for a clusterrandomized, multiple-crossover trial. Trials 2017;18.

44 Harris PA, Taylor R, Thielke R, et al. Research electronic data capture (REDCap)--a metadata-driven methodology and workflow process for providing translational research informatics support. J Biomed Inform 2009;42:377-81.

45 Schoenfeld DA, Bernard GR, ARDS Network. Statistical evaluation of ventilator-free days as an efficacy measure in clinical trials of treatments for acute respiratory distress syndrome. Crit Care Med 2002;30:1772-7.

46 Harhay MO, Wagner J, Ratcliffe SJ, et al. Outcomes and statistical power in adult critical care randomized trials. Am J Respir Crit Care Med 2014:189:1469-78.

47 Vincent JL, Moreno R, Takala J, et al. The SOFA (sepsis-related organ failure assessment) score to describe organ dysfunction/ failure. on behalf of the Working group on sepsis-related problems of the European Society of intensive care medicine. Intensive Care Med 1996;22:707-10.

48 , Ranieri VM, Rubenfeld GD, et al, ARDS Definition Task Force. Acute respiratory distress syndrome: the Berlin definition. JAMA 2012;307:2526-33.

49 Kidney Disease: Improving Global Outcomes (KDIGO) Acute Kidney Injury Work Group. KDIGO clinical practice guideline for acute kidney injury. Kidney inter 2012;2:8 https://kdigo.org/guidelines/acutekidney-injury/

50 Thygesen K, Alpert JS, Jaffe AS, et al. Fourth universal definition of myocardial infarction (2018). J Am Coll Cardiol 2018;72:2231-64.

51 Semler MW, Self WH, Wanderer JP, et al. Balanced crystalloids versus saline in critically ill adults. N Engl J Med 2018;378:829-39.

52 Zeger SL, Liang KY, Albert PS. Models for longitudinal data: a generalized estimating equation approach. Biometrics 1988;44:1049-60.

53 Turner RM, White IR, Croudace T, et al. Analysis of cluster randomized cross-over trial data: a comparison of methods. Stat Med 2007;26:274-89.

54 Parienti J-J, Kuss O. Cluster-crossover design: a method for limiting clusters level effect in community-intervention studies. Contemp Clin Trials 2007;28:316-23.

55 Beitler JR, Sarge T, Banner-Goodspeed VM, et al. Effect of titrating positive end-expiratory pressure (PEEP) with an esophagea pressure-guided strategy vs an empirical high PEEP-Fio2 strategy on death and days free from mechanical ventilation among patients with acute respiratory distress syndrome: a randomized clinical trial. JAMA 2019;321:846.

56 Munshi L, Ferguson ND. Evolving issues in oxygen therapy in acute care medicine. JAMA 2020;323:607. 